\title{
Un intento de autobiografía: la aspiración truncada de la madre María Ignacia del Niño Jesús
}

\author{
An Attempt at Autobiography: the Truncated Aspiration of Sister \\ Maria Ignacia del Niño Jesús
}

\section{Asunción Lavrin}

lavrin64@gmail.com

A comienzos del siglo XIX, una religiosa profesa en el convento de Santa Clara de Querétaro intenta escribir su autobiografía. Este poco conocido documento, en el cual la monja sólo llegó a narrar su vida hasta los siete años, ofrece información sobre la vida cotidiana en un hogar provinciano, donde vivía adoptada por una familia indígena. De igual importancia es el intento de la religiosa de reconstruir su niñez como predestinada a una vida espiritual que según ella se desarrollaba ya desde la primera infancia. El interés de la monja en autorrepresentarse como elegida de Dios a esa corta edad nos habla de un deseo literario y espiritual de reconfigurarse a sí misma, proceso que queda truncado debido a su fallecimiento, pero que amplia nuestra visión sobre el género autobiográfico.

PaLABRAS ClaVE: autobiografía, niñez y crianza infantil, visiones, prácticas religiosas y vida espiritual.

In the early 19th century, a nun at the Convent of Santa Clara de Querétaro sat down to write her autobiography. This little-known document, which only got as far as narrating the first seven years of her life, offers information on daily life in that provincial home, into which she was adopted by an indigenous family. Equally important is her attempt to reconstruct her childhood as if she had been predestined for the spiritual life that, she wrote, developed from earliest infancy. This nun's interest in representing herself as one of God's chosen at such an early age speaks to us of an attempt -both literary and spiritual- to reconfigure her person. Though the process was truncated by her death, her writings broaden our vision of the autobiographical genre.

KEYwORDS: autobiography, childhood and infant care, visions, religious practices, spiritual life.

Fecha de recepción del artículo: 20 de julio de 2015 / Fecha de aprobación: 26 de enero de 2016 / Fecha de recepción de la versión final: 26 de enero de 2016 
a autobiografía, como género literario e histórico, ha sido y sigue siendo objeto de análisis y estudio en el mundo académico e intelectual. Como "genero fronterizo", en palabras de José María Pozuelo Yvancos, comparte ficción y realidad, autorrepresentación del yo con información documental que pretende ser leída como testimonio verídico de eventos experimentados por el sujeto que se retrata a sí mismo. ${ }^{1}$ Pocos estudiosos de este género literariohistórico se dedicaron al estudio de la autobiografía de religiosas españolas hasta hace apenas veinte años, cuando las obras de Isabelle Poutrin y Sonja Herpoel abrieron ese mundo a nuestra lectura. Más recientemente, Fernando Durán López le ha dedicado otra monografía crítica. ${ }^{2}$ A pesar de la variedad de objeciones y argumentos en contra y en pro de la confiabilidad de esos textos como fuentes de conocimiento sobre quien escribe, no cabe duda que nuestro deseo como historiadores de encontrar datos confiables sobre el tiempo y circunstancias de los protagonistas autobiográficos puede rendir suficiente fruto para ameritar su abordaje. En el caso específico de religiosas enclaustradas, la autobiografía recoge un mundo íntimo que precisamente por ser subjetivo y autoconstruido nos permite un acercamiento que de otro modo sería imposible, aunque podemos decir que algunas autobiografías revelan más sobre quien se desea ser que sobre quien se es. Aun así, ese proceso de escogimiento de lo que se desea recordar es en sí significativo para nosotros. Como afirma Durán López, la autobiografía espiritual "es uno de los escasos espacios de autoexpresión que restan a sus autoras". ${ }^{3}$

${ }^{1}$ José María Pozuelo Yvancos, De la autobiografia. Teoría y estilos (Barcelona: Crítica, 2006), 22-33; Javier del Prado Biezma, Juan Bravo Castillo y María Dolores Picazo, Autobiografia y modernidad literaria (Cuenca: Universidad de Castilla-La Mancha, 1994).

${ }^{2}$ Isabelle Poutrin, Le voile et la plume. Autobiographie et sainteté féminine dans l'Espagne moderne (Madrid: Casa de Velázquez, 1995); Sonja Herpoel, A la zaga de santa Teresa: Autobiografia por mandato (Amsterdam: Rudopi, 1999) y "Un mar de misterios': la religiosa española ante la escritura”, en Breve historia feminista de la literatura española (en lengua castellana). Iv. La literatura escrita por mujer. Desde la Edad Media hasta el siglo XVIII, coord. Iris Zavala, 205-223 (Puerto Rico y Barcelona: Anthropos, Editorial de la Universidad de Puerto Rico, 1997); Fernando Durán López, Un cielo abreviado. Introducción crítica a una historia de la autobiografía religiosa en España (Madrid: Fundación Universitaria Española y Universidad Pontificia de Salamanca, 2007).

${ }^{3}$ Durán López, Un cielo, 116. Tanto Poutrin como Herpoel y Durán López enfatizan 
El objeto de este estudio, los recuerdos autobiográficos que dejó la madre María Ignacia del Niño Jesús, profesa en el convento de Santa Clara de Querétaro es un corto manuscrito inédito que apenas llena 28 páginas dobles, escrito posiblemente entre 1802 o 1803 , muy poco antes de su muerte. A pesar de sus limitaciones nos permite recoger el esfuerzo de una religiosa por rememorar y darle sentido a su niñez. ¿Quién fue María Ignacia del Niño Jesús? Nuestra protagonista nació en Irapuato, un pueblo entre Salamanca y Guanajuato en la zona fronteriza de los reales mineros del norte y parte del centro agrícola de México. María Ignacia vivió una situación socialmente ambigua. Hija de padres no conocidos, los papeles de admisión al convento la clasifican como española y expuesta en casa de una pareja de indios principales, Ignacio Santos Rodríguez y Petra Quiteria Parra. ¿Quién puede haber sido su padre biológico? La pareja adoptiva era tratada familiarmente en la casa de un rico mercader de la región, don Ignacio Asconobieta que bien pudo haber sido su padre, pero nada se puede asegurar al respecto. Su madre, sabemos, murió de parto, y jamás sabremos quien fue. La admisión en el convento de Santa Clara de Querétaro de una niña huérfana espańola criada por indígenas no se puede explicar sin el apoyo de algún poderoso y discreto patrón local. ${ }^{4}$

Antes de iniciarnos en el estudio de esta autobiografía es aconsejable saber hasta qué punto esta fuente es similar a otras autobiografías o biografías que conocemos, especialmente en cuanto a describir y analizar la propia niñez. Las autobiografías de religiosas en Hispanoamérica y especialmente en Nueva España son poco frecuentes. ${ }^{5}$

como las autobiografías, como resultado de mandatos de confesores o directores espirituales, padecen de muchas restricciones interiores tanto en el autoanálisis y proceso de recordación, como en la construcción formal de la escritura.

${ }^{4}$ Sobre el convento de Santa Clara, véase Mina Ramírez Montes, Niñas, doncellas, virgenes eternas. El convento de Santa Clara de Querétaro (México: unam, 2005). Asunción Lavrin, "La religiosa y su confesor: Epistolario de una clarisa mexicana, 1801-02", Archivum Franciscanum Historicum (105) (enero-diciembre 2012): 455-478; "Visiones y devociones. Maria Ignacia del Niño Jesús a través de su epistolario", en Vida conventual femenina. Siglos XVI-XIX, comp. Manuel Ramos Medina, 345-375 (México: Centro de Estudios de Historia de México-Carso, 2013).

${ }^{5}$ Rosalva Loreto López, "Escrito por ella misma. Vida de la Madre Francisca de la Natividad", en Monjas y beatas. La escritura femenina en la espiritualidad barroca novohis- 
En el siglo XVII novohispano tenemos la cuasiautobiografía de sor Juana Inés de la Cruz en carta que conocemos como "La Respuesta a sor Filotea". Aunque sor Juana provee datos valiosos sobre su niñez, sus estudios, sus deseos intelectuales de sobreponerse a las limitaciones de su sexo, sus conexiones familiares y cortesanas una vez en la capital novohispana y sus razones para tomar el velo, "La Respuesta" no se puede categorizar como una autobiografía, a pesar de ser una joya literaria. ${ }^{6}$ Por otra parte, la muestra que nos dejó sor María Ignacia del Nino Jesús está cercana en espíritu y estilo a los de otras monjas del periodo virreinal. En términos comparativos tenemos tres autobiografías en el siglo xvir: la madre María Magdalena Lorravaquio, la madre Francisca de la Natividad y la madre María de San José. Ni la madre Lorravaquio ni Francisca de la Natividad nos dicen mucho de su niñez. ${ }^{7}$ La madre María de San José, profesa en el convento de Santa Mónica de Puebla, por otra parte, sí dejó amplia información sobre su vida como secular antes de su profesión. La misma ha sido estudiada por Kathleen Myers y es el mejor ejemplo que tenemos a mano de información sobre la nińez y la fa-

pana. Siglos XVII y XVIII, ed. Asunción Lavrin y Rosalva Loreto López, 24-66 (Puebla: Universidad de las Américas, Archivo General de la Nación, 2002) y "Las formas de escritura femenina, un aporte a la espiritualidad barroca novohispana. Siglos XVII y XVIII", en $\mathrm{Ca}$ mino a la santidad, siglos XVI-XX, coord. Manuel Ramos Medina, 69-82 (México: Condumex, 2003); Doris Bieñko, "Voces del claustro. Dos autobiografías de monjas novohispanas del siglo xvı", Relaciones. Estudios de Historia y Sociedad xxxv (139) (verano 2014): 157-194; "Los territorios del yo. La autobiografía espiritual en la época virreinal", en De sendas, brechas y atajos. Contexto y crítica de las fuentes eclesiásticas, siglos XVI-XVIII, coords. Doris Bieńko de Peralta y Berenise Bravo Rubio, 36-60 (México: EnAH, INAH, Conaculta, Promep, 2008); Tatiana Navallo, "La autobiografía conventual colonial", Andes (14) (2003): 1-30, también en http://www.redalyc.org/pdf/127/12701402.pdf; Asunción Lavrin, "La vida femenina como experiencia religiosa: biografía y hagiografía en Hispanoamérica colonial, Colonial Latin American Review 2(1-2) (1993): 27-51.

${ }^{6}$ Sor Juana Inés de la Cruz, "Respuesta de la poetisa a la muy ilustre sor Filotea de la Cruz”, en Obras completas (México: Editorial Porrúa, 1969), 973-996; Margo Glantz, Sor Juana Inés de la Cruz: ¿Hagiografía o autobiografía? (México: Grijalbo, UNAM, 1995).

${ }^{7}$ Asunción Lavrin, "La madre María Magdalena Lorravaquio y su mundo visionario”, Signos Históricos (13) (enero-junio 2005): 22-41; Emilio Ricardo Báez Rivera, Visiones y experiencias extraordinarias de la primera mistica novohispana. Autobiografía de una pasionaria de amor de Cristo (México: Derechos reservados, 2013); "Symbolica mystica: la venerable María Magdalena de Lorravaquio Muńoz y sus tangencias con lo sagrado prehispánico", en Manuel Ramos Medina, comp., Vida conventual femenina, 55-64. 
milia de una religiosa en ese siglo. ${ }^{8}$ En el siglo XviII hay otro intento de autobiografía, el de la madre María Marcela Soria, estudiado por Asunción Lavrin. . Sor María de San José y sor María Marcela Soria escribieron mesurada y conscientemente sobre su niñez y vida familiar. La influencia de la Vida de Teresa de Jesús es obvia en muchas monjas novohispanas -sea implícita o explícita ya que Teresa fue lectura muy frecuente en los claustros- ${ }^{10}$ También podemos esperar la influencia de las vidas de santos por ser ubicua fuente espiritual en los conventos. Entre ellos, santa Catalina de Siena y santa Gertrudis la Magna parecen haber sido las que más influyeron en los claustros novohispanos. ${ }^{11}$

Dado el hecho de que la autobiografía de la madre María Ignacia cubre sólo unos pocos ańos de su vida, la primera pregunta que se puede hacer sobre la misma es hasta qué punto es comparable con la presentación de la niñez en biografías de monjas o de religiosos. En general, los datos que usualmente aportan esas biografías sobre ese periodo de la vida son escasos. Para la mayor parte de los biógrafos

${ }^{8}$ Kathleen Myers, "Fundadora, cronista y mística, Juana Palacios Berruecos/Madre María de San José (1656-1719)”, en Monjas y beatas, Lavrin y Loreto, 67-110; Word from New Spain. The Spiritual Autobiography of Madre Maria de San José (1656-1719) (Liverpool: Liverpool University Press, 1993); con Amanda Powell, A Wild Country Out There in the Garden. The Spiritual Journals of a Colonial Mexican Nun (Bloomington: Indiana University Press, 1999); Mario A. Ortiz, ed., La autobiografia espiritual de la Madre María de San José (1656-1719) (Newark: Juan de la Cuesta, 2011).

${ }^{9}$ Asunción Lavrin, "María Marcela Soria: Una Capuchina queretana”, en Diálogos espirituales. Manuscritos femeninos hispanoamericanos. Siglos XVI-XIX, Asunción Lavrin y Rosalva Loreto, 74-116 (Puebla: BuAP, udLA, 2006). Su confesor, Diego de Segovia, la instó a escribir su vida, que nunca se publicó ya que hubo objeciones inquisitoriales a su contenido.

${ }^{10}$ Teresa de Jesús, Libro de la vida, prólogo de Joseph Pérez, edición de Ma. de los Hitos Hurtado (Madrid: Algaba Ediciones, 2007). Sobre la vida de santa Teresa, véase Alison Weber, "The Three Lives of the Vida: The Use of Convent Autobiography", en Women, Texts and Authority in the Early Modern Spanish World, eds. Mara V. Vicente y Luis R. Corteguera, 107-125 (Londres: Ashgate, 2003); Isidoro Aren Janeiro, "Libro de la Vida de Teresa de Jesús: Teresa de Cepeda y Ahumada reconstruida por Teresa de Jesús", en Mujeres, espacio y poder, ed. Mercedes Arriaga Florez et al., 17-26 (Sevilla: Arcibel Editores, 2006).

${ }^{11}$ Antonio Rubial y Doris Bieñko de Peralta, "La más amada de Cristo. Iconografía y culto de santa Gertrudis la Magna en Nueva España”, Anales del Instituto de Investigaciones Estéticas (83) (2003): 1-53. 
de religiosos, la nińez no era una etapa importante en la formación de la espiritualidad -aunque sí de la formación religiosa y devocional- ${ }^{12}$ Los biógrafos no contaban con información directa de sus sujetos, que podían haber ya fallecido o, en el mejor de los casos, su información les llegaba de segunda mano de personas que habían conocido al sujeto biografiado. Los biógrafos y cronistas religiosos novohispanos tuvieron cierta preferencia por la pintura de una vida en la cual la nińez sería el preámbulo de la profesión y la vida virtuosa. Esta característica se aplica a las biografías de mujeres profesas, en las cuales se citan eventos que presagiaban la profesión y cualidades de virtud infantiles que después florecerían en el claustro. Por otra parte, la nińez de algunos santos no fue necesariamente "santa" ni ofrecía indicación de la profesión o grado de vida espiritual que se alcanzaría a través de la vida. ${ }^{13}$ En estos casos, la espiritualidad de la edad madura se presenta en contraste con la puerilidad de los primeros ańos.

Contra ese telón de fondo tenemos que ubicar y estudiar las noticias que nos ha dejado la madre sor María Ignacia que si bien se centran en su niñez también nos dicen mucho sobre la personalidad de la religiosa ya adulta. Estudiar una autobiografía que quedó truncada en medio de la nińez parece una proposición un poco descabellada, pero en vista de la información que tenemos ya acumulada sobre esta religiosa, no se puede dejar de lado el esfuerzo que la llevó a iniciar ese proyecto y que parece haber sido el último de su corta vida. La autobiografía consta de dos cuadernos; uno tiene 8 páginas

${ }^{12}$ Asunción Lavrin, "La construcción de la niñez en la vida religiosa. El caso novohispano", en Historia de la infancia en América Latina, coord. Pablo Rodríguez y María Emma Manarelli, 121-144 (Bogotá: Universidad Externado de Colombia, 2007); Cristina Ruiz Martínez, "La moderacion como prototipo de santidad: una imagen de la niñez", en De la santidad a la perversion o de por qué no se cumplia la ley de Dios en la sociedad novohispana (Mexico: Editorial Grijalbo, 1986), 49-66; Isabelle Poutrin, "Souvenirs d'enfance: L'apprentissage de la sainteté dans l'Espagne moderne", Mélanges de la Casa de Velázquez (23) (1987): 331-354.

${ }^{13}$ Véase un estudio comparativo de los recuerdos de la nińez de santos varones y mujeres medievales en Rosalyn Voadern y Stephanie Volf, "Visions of my Youth: Representations of Childhood of Medieval Visionaries", Gender and History 12(3) (noviembre 2000): 665-684. 
dobles (o sea 16 páginas) y está numerado como cuaderno 2 . El segundo, 11 páginas dobles (o sea 22) y está numerado como cuaderno 3. En total son 38 páginas pequeñas, escritas apretadamente sin desperdicio de papel. ${ }^{14}$ En el cuaderno 2 dice comenzar su tercer año de vida y, dada la numeración, sugiere que la religiosa había escrito un primer cuaderno que se ha perdido y que pudo contener información sobre su nacimiento y familia.

El esfuerzo autobiográfico se ha conservado gracias a la relación epistolar y espiritual que María Ignacia sostuvo con el dieguino valenciano, Fr. Manuel Sancho Valls, su director espiritual, a quien escribió 76 cartas. Hay una portada para el manuscrito autobiográfico que indica que Valls pidió la autobiografía a la religiosa, situación similar a la de otras religiosas que tomaron la pluma para ese fin, tanto en Nueva Espańa como en España. El texto de la portada explica que se busca inspiración espiritual en la Santísima Trinidad y la Sagrada Familia y se dirige al "provecho de los desterrados hijos de Eva y esfuerzo de pusilánimes". Puede haber sido escrito por Valls, quien lo destinaría a una biografía ejemplarizante, siguiendo la huella de otros esfuerzos coordinados entre religiosa y confesor. ${ }^{15}$ Cuando el padre Valls marcha a Puebla en el verano de 1802 -posiblemente bajo orden superior- todos los planes biográficos y autobiográficos se vinieron a tierra. De hecho, parece que la vida misma de la religiosa se desmoronó. Cesaron sus cartas, se interrumpió su autobiografía y

${ }^{14}$ Archivo Histórico de la Provincia Franciscana de Michoacán (AHPfM), Celaya, México. Fondo Santa Clara de Querétaro, caja 1, exp. 1, cuadernos 2 y 3 y portada. La escritura de estos cuadernos puede situarse tentativamente en 1802 . Hay una portada que así lo estipula. En el cuaderno 3 dice tener ya 6 ańos de edad.

${ }^{15}$ Como ejemplos de biografías publicadas en México, véanse Fr. Joseph Gómez, Vida de la venerable madre Antonia de san Jacinto... hija el real ... convento de santa Clara de Jesús ... de Querétaro (México: Imprenta de Antuerpia, 1689); Joseph Bellido, Vida de la venerable madre sor Mariana Ana Águeda de San Ignacio, primera priora del religiosísimo convento de dominicas recolectas de Santa Rosa de la Puebla de los Ángeles (México: Imprenta de la Biblioteca Mexicana, 1758); Pedro Salmerón, Vida de la venerable madre sor Isabel de la Encarnación, carmelita descalza natural de la ciudad de los Ángeles (México: Francisco Rodríguez Lupercio, 1675); Antonio Rubial, "Imprenta, criollismo y santidad. Los tratados hagiográficos sobre venerables, siervos de Dios y beatos novohispanos", REDIAL, Revista Europea de Información y Documentación sobre América Latina 8(9) (2001): 4352, 117-131. 
murió poco después. El padre Valls conocía bien a María Ignacia. Por cerca de diez meses entre 1801 y 1802 habían sido padre e hija espiritual y habían intercambiado numerosas cartas y papeles. Mi estudio de esa correspondencia indica una inusitada intimidad entre ambos y sugiere que la religiosa, por su parte, tenía cierto conocimiento de las interioridades del padre Valls. Esto no significa que debemos descartar en modo alguno la posibilidad de que el padre peticionó la autobiografía para establecer la ortodoxia de la vida espiritual de la monja. Ambos propósitos se podían conjugar fácilmente.

\section{LA NIÑEZ PARRA}

Lo que conocemos sobre la niñez secular de las mujeres hispanoamericanas y de las profesas en religión es relativamente poco y este documento aporta datos sobre una vida fuera de lo común. ${ }^{16} \mathrm{La}$ niñez de María Ignacia tuvo características especiales dadas las circunstancias sociales y familiares ya descritas. Lamentablemente, sólo podemos atisbar una parte muy reducida porque la autora supeditó su memoria a su deseo de autodescribirse como predestinada espiritual. María Ignacia del Niño Jesús deseaba probar que, ya desde los albores de su vida, era favorecida por Dios. Cómo se lleva a cabo ese proceso es de tanto interés como la obtención de datos de la vida real, pero es necesario deslindar sus territorios respectivos. Veamos los datos de la vida real.

Ante todo, se nota la precocidad. La religiosa reclama que todo lo que cuenta ocurrió entre los 3 y los 6 o 7 años de vida. Esta característica sigue las huellas de las biografías de santos o de personas notables dentro de las órdenes religiosas. Es muy posible que María Ignacia haya oído tales historias en su niñez, pero no podemos descartar lo que aprendió ya de adulta y en el convento. Como mujer relativamente educada en una cultura religiosa no es de extrańar una proyección de sus lecturas sobre su propia experiencia infantil y esa presunción de precocidad religiosa que permea su autobiografía. La

${ }^{16}$ Asunción Lavrin, "La construcción de la niñez", 121-144; Isabelle Poutrin, "Souvenirs d'enfance", 331-354. 
niñez de María Ignacia es peculiar e intrigante como una nińa blanca criada por indígenas en una pequeńa ciudad provinciana. El personaje más importante en su vida familiar fue su nana, como llamaba a su madre adoptiva indígena. Nunca la llama "madre". Notable por su ausencia es el esposo de María Quiteria Parra, su padre putativo. Su único "padre" durante esos primeros ańos de su vida fue el confesor que tuvo desde la edad de tres ańos y que falleció cuando parece tenía cerca de siete años y a quien llamaba Tata Padre. No hay mención alguna de hermanos u otros familiares cercanos. En su entorno familiar había sirvientas que tampoco dejan huellas en este documento, pero que nos indica que vivió en una familia con suficientes medios económicos. Otras personas mencionadas como visitas de la casa son varias señoras, su "padrino", así como algunos frailes franciscanos. El "padrino" es posiblemente su confesor ya que comenta como tomó la comunión de sus manos. ${ }^{17}$ La ausencia de la figura de una madre reconocida como tal se redimirá con la presencia de la virgen María, quien se le aparece en el santuario de Nuestra Señora de San Juan de los Lagos, y le promete ser madre de ella. "Yo te asistiré como madre tuya y dispondré que cada ańo vengas a este mi santuario para que te consueles y animes". ${ }^{18}$ Esta ausencia de familiares es peculiar y puede haber sido intencional. Si María Ignacia pretendía centrarse en su propia experiencia, y si hubo un rechazo subconsciente hacia su familia adoptiva, la ausencia de otros miembros de la familia resulta explicable.

Se describe personalmente como de muy pequeña estatura. A los tres ańos era muy pequeńa de cuerpo, pareciendo una nińa de ańo y medio o dos años que necesitaba caminar tomada de la mano de un adulto en la calle. ${ }^{19}$ Para tomar la comunión tenía que pararse sobre una viga para poder recibir el sacramento. Físicamente su ascendencia española se ratifica al describir que durante una visita de varias señoras a su casa, le halagaban porque "tenía muy huero (güero) el

${ }^{17}$ Cuaderno 3, fol. 3v. María Ignacia vivió en casa de Ignacio Santos Rodríguez y doña Petra Quiteria Parra, indios principales, cacique y originarios de la congregación de Irapuato.

${ }^{18}$ Cuaderno 2, fol. 6v.

${ }^{19}$ Cuaderno 2, fols. 1-1v. 
cabello mucho y grande, y muy lindas pestańas y cejas negras". ${ }^{20}$ No se aclara si esas señoras eran españolas o no, ya que nunca menciona ninguna identidad racial. María Ignacia se describe como una niña voluntariosa que rechaza halagos y regalos y toma resoluciones contrarias a los deseos de su familia. Así, al recibir el halago por su cabello, su reacción fue negativa:

Luego que oí esto tomé unas tijeras y me corté los más del cabello y todas las pestańas y cejas para que no me volvieran a decir. No reflejaron en que me había cortado todo esto hasta otro día que me levantaron y me vieron que nada de pestańas y cejas me había dejado y que todo el cabello me lo había cortado y la trenza que me había quedado estaba quemada con la vela. Mucho por esto me castigaron y pasé más amarga vida.

En otra ocasión recuerda como la seguían vistiendo y adornando "con los adornos de moda" y la castigaban si no mantenía su compostura. Cuando recordaba que le decían que parecía una "muñeca”, la monja ya adulta comenta si la querrían tanto como unas muñecas que le habían regalado. ${ }^{21} \mathrm{Al}$ recordar este incidente, la monja nos está sugiriendo un rechazo hacia cualquier indicación de que su cuerpo era atractivo y podía llamar la atención. Pero, si nos situamos en un plano más cercano a la decisión de una niña de su edad, creo que también podemos ver un rechazo a quienes la halagaban y una voluntad de hostilidad contra quienes la rodeaban. Nos recuerda como santa Teresa eventualmente desechó la vanidad de las ropas.

Respecto a castigos corporales los menciona varias veces. La pedagogía de la crianza infantil en el siglo XviII incluía las penitencias corporales. En varias ocasiones de comportamiento objetable para los adultos la nińa recibía azotes. Por ejemplo, cuando se escondió en la azotea de un troje de maíz por estar atemorizada de una rińa en la calle. ${ }^{22}$ La monja María Ignacia aun recordaba esos castigos cuando escribía a sus 34 ańos de edad, pero reinterpretándolos como

\footnotetext{
${ }^{20}$ Cuaderno 2, fol. 6 .

${ }^{21}$ Cuaderno 3, fol. 7.

${ }^{22}$ Cuaderno 2, fol. 6.
} 
deseos del Señor que permitía la aborrecieran en la casa. En un breve comentario sobre su nana la caracteriza como de "genio duro" ${ }^{23}$ No cabe duda que la religiosa fue una niña difícil en algunos momentos, y que ya desde temprano encontraba problemas en explicarse su situación en una familia de diferente etnia. El recuerdo de su niñez no le causaba alegría alguna. Y resulta obvio que su deseo, ya como monja, fue el de presentar una nińez carente de afectividad personal. Esto nos llevaría a comprender su refugio en la religión.

Otra conducta objetable y también de resistencia contra la familia fue el hecho de que echó en un pozo unas muñecas que le habían regalado unas visitas. Después de forzarla a aceptarlas y ponerlas en un cajoncito para que las llevara al patio a jugar, dice que había venido un "niño" que la ayudó a tirar las muñecas al pozo, otro acto de repudio y hostilidad hacia su familia. ${ }^{24}$ En otra ocasión fue castigada por haber pedido al Señor le quitara una enfermedad de los ojos a otra niña y que se la diera a ella, gesto que trasluce cierta conciencia religiosa y caritativa en la pequeña, pero también de intransigencia de la familia, que posiblemente creyera a pie juntillas que le podía atraer un castigo divino por ser insolente ante la voluntad de Dios. Sin embargo, cuando al día siguiente amaneció casi ciega de un mal en los ojos que, según ella, padeció por tres meses, su nana recurrió a la devoción y consuelo de su religión y prometió a la imagen de Nuestra Señora de San Juan de los Lagos que le daría lo que pesara María Ignacia en cera, pagar por nueve misas y llevarla a velar a Dios en el santuario si la curaba de su enfermedad. Obviamente la familia vivía dentro de un clima religioso en el cual existían castigos divinos ante los cuales los humanos deberían rendirse y suplicar por el perdón. Inevitablemente, dentro del ambiente de religiosidad de su casa y su tiempo, nos cuenta que tuvo lugar una curación "milagrosa” y la nana cumplió su promesa, aunque tuvo que esperar por dos meses, ya que los médicos aconsejaron no viajar hasta que la nińa estuviera más recuperada. Detalles como éstos, nos abren la puerta de la casa familiar como una en la que la devoción mariana era res-

${ }^{23}$ Cuaderno 3, fol. 1v y 6v.

${ }^{24}$ Cuaderno 2, fol. 4. 
petada y la nana demostraba su preocupación por la niña a su cargo. También nos hablan de la realidad de la cultura popular religiosa alrededor de los santuarios marianos, de los cuales, San Juan de los Lagos era muy querido entre los indígenas, lo que explica la devoción de su "nanita" por esa imagen. ${ }^{25}$

Hasta aquí se percibe una vida provinciana en una casa de indígenas relativamente acomodados. Sus padres adoptivos la vestían bien y recibía regalos y nos podemos preguntar si recibirían ayuda económica del padre biológico. También se preocupaban por su alimentación y salud. Se usaban remedios caseros para las enfermedades, pero en casos más graves se llamaba a un experto. Por ejemplo, cuando las disciplinas que dice se infligía y la falta de sueńo la pusieron "flaca y descolorida" su nana llamo a un médico, quien determinó que estaba muy débil y recomendó que le diesen "harto de comer". Aunque ella se propuso no pedir comida, expresión de su testarudez infantil, la recibía cuando se la daban y, escribe, "poco a poco fui engordando hasta que quedé en buena proporción y poniéndome de buen color como hasta el día que escribo". ${ }^{26}$

\section{LA VIDA ESPIRITUAL Y LA VOCACIÓN RELIGIOSA DE LA NIÑA María IgNaCia}

La vida familiar se complica con la vocación religiosa que María Ignacia dice haber tenido desde sus tres ańos cuando se inicia el cuaderno 2 de sus memorias autobiográficas. Los elementos de la vida diaria que conocemos están íntimamente ligados a sus prácticas religiosas, en las cuales participan su nana y otro personaje clave, el cura párroco que visitaba la familia y que la niña tomó como su director espiritual en el desarrollo de su vocación. Petra Quiteria Parra mantenía una vida devocional propia que permitía a la pequeña alinearla a la suya. La nana la llevaba a la iglesia, le permitía tomar la

${ }^{25}$ Cuaderno 2, fol. 6. Nuestra Señora de los Lagos fue una devoción establecida desde el siglo XVII. La virgen del Pueblito era otra devoción mariana, que aparece en sus cartas al director espiritual y que fue muy favorecida en Querétaro y entre las clarisas de esa ciudad.

${ }^{26}$ Cuaderno 2, fol. 4. 
comunión muy tempranamente, y la llevó a un santuario para su curación. ${ }^{27}$ No cabe duda que vivió con una familia devota y creyente que conocía de su inicio en disciplinas y rezos y hasta cierto punto los acomodaba, aunque es difícil saber cuál fue el grado de tolerancia. Cuando María Ignacia hizo un pacto de ayunar tres veces a la semana, se las arreglaba para que se le cayera el pozuelo de las manos y se manchaba la ropa, por lo cual recibía azotes y la castigaban dejándola en ayunas hasta mediodía, que era su intención. Repetía las mismas tácticas con las otras comidas, con el resultado de que la castigaran dejándola sin comer hasta el día siguiente. ${ }^{28}$ Se comprueba así, que la piedad familiar tenía ciertos límites de tolerancia o comprensión cuando se trataba de corregir lo que aparecía como mala conducta en una niña desobediente.

Respecto al párroco local lo identifica como su "padre" y fue en él que encontró un sustituto para el esposo de Petra Quiteria Parra. Es a través de ese párroco que se inicia en la imitación de la vida religiosa. El clérigo, cuyo nombre no menciona, era un anciano tolerante, quizás deseoso de ser el promotor de una esposa de Cristo. Sus visitas vespertinas a la casa indican una costumbre provinciana de hospitalidad a una figura de autoridad religiosa en el pueblo. Entre él y la nińa se estableció una conexión en la cual ella demostró su avidez por una figura paternal. Tomando la iniciativa de establecer un lazo afectivo María Ignacia comenzó a asediarlo para que le permitiera tomar la comunión. El párroco la sometió a un examen preguntándole sobre sus oraciones, y quedando admirado de cuan bien las sabía la premiaba dándole dinero para dulces y frutas, que ella escribe haber usado para comprar bulas por las ánimas. Tras el examen de su conocimiento de varias oraciones como el Credo, de los diez mandamientos y del misterio de la Santísima Trinidad, el clérigo llegó a la conclusión de que la niña tenía perfecto uso de razón para tomar la primera comunión y así se lo comunicó a doña

${ }^{27}$ Cuenta que entre los tres y seis ańos el diablo la metía en el horno de cocer pan y la sometía a abusos físicos. Las quemaduras eran obvias a la familia que creía (posiblemente con alguna certitud) que la niña metía la cabeza y los brazos en el horno. La fascinación del fuego a esa edad no es rara.

${ }^{28}$ Cuaderno 2, fol. $7 \mathrm{v}$. 
Petra. Entonces la niña usó su persuasión para alcanzar su objetivo. Según ella, le pidió al cura no le diera dinero sino que le permitiera tomar la comunión ya que cumplía los requisitos. ${ }^{29} \mathrm{El}$ padre le concedió el derecho de confesión en dos días y ella le rogó fuera él mismo su confesor. La preparación para su primera comunión -en sus palabras- fue muy seria, colmada de penitencias físicas y dudas espirituales. Además de tener pesadillas de que la querían ahogar tuvo una visión en la que vio tres manos que nacían de un solo brazo y otra mano empuñando una espada, los símbolos de la Santísima Trinidad y san Miguel. Según ella no podía sujetar "los ímpetus que tenía" respecto a las disciplinas preparatorias, que eran de sangre, y que creía eran necesarias para tomar la comunión. ${ }^{30}$

Ya en calidad de director espiritual, el párroco lloró cuando la niña le pidió le diera un voto de castidad, y accedió a dárselo por sus propias manos, pronosticándole una vida difícil hasta los 33 ańos de edad, pero aun peor después de esa edad. Estos recuerdos posiblemente se verían confirmados por la religiosa si su autobiografía hubiera sido completada. No se explica de otro modo la elección de ese recuerdo tan profético a una edad tan temprana. Al parecer poco tiempo después muere el anciano párroco confesor, lo cual dio pie a María Ignacia para contar la experiencia de esa muerte y lo que significó para ella. Es el testimonio de una nińa que asiste a la iglesia donde está expuesto el cadáver del clérigo que tuvo tanta importancia en sus primeros años. Fue acompañada por su nanita, quien la instó a encargar cuatro velas de velación y besar los pies y las manos del difunto. ${ }^{31}$ María Ignacia confiesa haberle estimado mucho y

${ }^{29}$ Respecto a dar la primera comunión a los niños, se requería un periodo de instrucción de un año y se les admitían confesiones de sus pecados durante ese tiempo. Dichos pecados eran mentir, desobedecer, decirse injurias los unos a los otros y otras formas de "mala conducta" infantil. La edad apropiada para la primera comunión quedaba a la discreción del confesor, que usualmente citaba la "edad de la razón”. Usualmente un niño se consideraba apto a los siete ańos, pero era posible que personas de 18 a 20 ańos nunca hubieran comulgado por no estar instruidos en el catecismo. Al respecto véase Anselmo Petite, Conducta de las almas en el camino de la salvación. Suplemento a la conducta de confesores (Madrid: Imprenta de Son Josef Urrutia, 1792), 12, 13-18.

\footnotetext{
${ }^{30}$ Cuaderno 2, fol. $1 \mathrm{v}-2 \mathrm{v}$.

${ }^{31}$ Cuaderno 3, fol. 1-1v.
} 
cumplió su obligación "con mucho dolor". Tras cumplir con los deseos de su nana siguió un momento aterrador. Hincada de rodillas como estaba, escribe que el cadáver extendió la mano, la agarró por el cuello y comenzó a darle un postrer mensaje en el cual le aclaraba que Dios no la había abandonado, pero estaba escondido para probar su amor y constancia. Inmediatamente, el fallecido le pidió rogara por su alma y las de las santas ánimas del purgatorio, encargándole además que buscara un buen confesor que la llevara por el camino del Señor. Después de bendecirla, el cadáver retiró la mano y adoptó su postura yacente.

Alejándose, María Ignacia se hincó de rodillas a rezar y entonces tuvo una visión de las ánimas del purgatorio incluyendo la del cura, tal y como lo pintaban (en cuadros religiosos) "entre llamas, y amarradas con cadenas”. Estas ánimas le siguen pidiendo que las ayude, lo cual la mueve a hacer el voto de las Ánimas y promete nunca olvidarlas. La influencia pictórica del purgatorio sobre la imaginación infantil se expresa en este incidente que nos revela cuan tempranamente se asimilaban los conceptos fundamentales de la religión y el efecto que ejercían tanto pinturas como narrativas orales sobre la formación de hábitos piadosos. Después de este incidente se dirigió a la fuente de agua bendita y comenzó a dispensarla a las ánimas que dice haber visto. Así se inició una práctica frecuente, pues, sacaba agua del pozo de la casa y le pedía a los franciscanos que venían a visitar la casa las bendijera para usarla con las ánimas. El inusitado e increíble incidente del cadáver que se mueve, le habla y le da su último mensaje, es parte de una serie de visiones que se asemejan mucho a las que tenía de adulta y describe en sus cartas al confesor Manuel Sancho Valls. También confirma la profunda y popular preocupación y devoción por las ánimas del purgatorio prevalente en el México virreinal. Por otra parte, el recuerdo de ese párroco la seguía asediando en su vida y nos hace comprender la profunda huella emocional que dejó en ella. El mismo personaje reaparece en otra visión durante las devociones de semana santa, en ese caso rodeado de niños y nińas:

Entendí en esto que por la mucha caridad que había tenido y la comprensión con que amparaba a los nińos pobres y nińas, que por eso estaban 
pendientes de su cuello. Unos porque habiendo muerto siendo chicos estaban en el cielo; otros que aun vivían suspiraban por aquel Señor cura que los había visto y amparado como a hijos. Mucho gusto me dio haber visto al dicho Señor. Lo abracé, y dándome la Santísima Trinidad su bendición, y lo mismo la sagrada familia y santos que he dicho, volví a mí y me hallé en el pesebre. ${ }^{32}$

Otra expresión de devoción asequible a una niña de su edad, ya convencida de su comunión personal con los seres divinos, fue la de procurar la caridad con el prójimo, que tácitamente nos habla de su situación acomodada ya que tenía suficiente para dar a otros. Recuerda especialmente el dar ropas a los desposeídos que veía en la calle, simplemente quitándose las propias. ¿Habría conocido los actos de caridad franciscana, dada su conexión con la Orden? Estas actividades caritativas no fueron bien vistas por su familia, pero al recordarlas y escribir sobre ellas, María Ignacia iba construyendo la figura de una niña virtuosa a pesar de la oposición familiar. Tras hacer su voto de castidad recibió unas bulas y dinero del párroco. Ese dinero lo empleó en comprar pan y cigarros para los presos de la cárcel, a quienes visitó. ${ }^{33}$

Otro rasgo importante de esta corta narración es la práctica de disciplina corporal iniciada a temprana edad. Usaba cilicios que se ponía cada mañana, y practicaba penitencias de sangre en un pesebre-corral distante de la casa. Parece haber sido posible ocultar los cilicios lo que sugiere que tenía que vestirse ella misma y que nadie se tomaba el trabajo de registrar sus ropas. Por otra parte en la casa parece no haber existido ninguna aprensión respecto a su retiro a un pesebre alejado de la casa donde hacía oraciones y penitencias. Las prácticas de disciplinas de sangre fueron descubiertas por su padrino que llegó inesperadamente a visitarla. De la casa la llamaron a que se

${ }^{32}$ Cuaderno 3, fol. 3v.

${ }^{33}$ Es de interés comparar estos actos de generosidad con otros de similar naturaleza recordados por sor María Marcela Soria. Ambas tuvieron la oportunidad de contar con recursos económicos que les permitieron probar su veta caritativa, aunque la familia de María Marcela era de mucho mayor rango social. Véase Biblioteca Nacional, México, Vida de la Madre María Marcela, religiosa Capuchina del convento de Querétaro, copia, 1844, fols. 13-14. 
presentara, pero al no haber oído la llamada y no regresar, el caballero se acercó al pesebre y la descubrió en acto flagrante, comprobando las huellas de sangre de las disciplinas. María Ignacia recordaba muy bien la escena después de tantos años. El padrino tosió discretamente antes de entrar, lo cual le dio tiempo a ella para esconder la disciplina, pero la evidencia de la misma en su cuerpo fue obvia. El padrino la regañó y le preguntó quién le había enseñado tales destrozos, señalándole cuánto podrían quebrantar su salud, especialmente, siendo tan pequeña de cuerpo. Le prohibió volviera a disciplinarse y cuando la regresó a la casa informó a la nana de las prácticas. A pesar de que no se pudo encontrar el instrumento de la disciplina, la tuvieron a raya por un tiempo, no dejándola sola ni permitiéndole ir al pesebre. ${ }^{34}$

En su terquedad y determinación de vencer las restricciones, María Ignacia dice haber inventado formas de disciplinar el cuerpo bajo capa de travesuras, como cargar piedras pesadas pretendiendo eran juegos, y experimentado el dolor de los cilicios de soga que llevaba puestos y que eran su ofrecimiento personal a Dios. Aunque comía y dormía poco, comenta que su mortificación era no poder mortificarse. ${ }^{35}$ María Ignacia escribe haber seguido sus prácticas a medida que la familia se desentendió del asunto y ella logró evadir la supervisión. Cuando la dejaban sola en casa, y cuando podía, se iba a su pesebre a disciplinarse. Cuenta que san Francisco y san Pedro de Alcántara la incitaban a las disciplinas y le enseñaron como ocultar la sangre con tierra.

Un recuerdo de semana santa nos habla del devocionario y ritual provincial, de la influencia del padrino en su hogar, y de la continuada práctica de disciplinas corporales. Necesitado de suplir a un niño en la procesión que acompañaba la representación de la pasión, el padrino se aparece en su casa con un peluquero y un "moro" con un cajón en el cual había un vestido de ángel, para que María Ignacia fungiera como ángel para una procesión. La nana dio su permiso y se aprestó a María Ignacia con lavamiento de pies, brazos

${ }^{34}$ Cuaderno 3, fol. 5v.

${ }^{35}$ Cuaderno 3, fol. 7. 
y cara, y una bebida de chocolate en vez de comida. Los recuerdos respecto a la procesión no fueron placenteros. El peluquero le tiró del cabello; los vestidos le apretaban los cilicios que usaba, así como los alfileres que llevaba puestos se le hundían en la carne. No declaró nada a la familia. Colocada primero cerca de la cruz escuchó la voz del Señor que elogiaba su presencia y compañía, pero más adelante en la procesión, caminando muy cerca de la urna donde yacía el cuerpo, la niña lloraba amargamente no sólo por el espectáculo, sino por los pellizcos que recibía por no entonar bien las canciones y versos que acompañaban el santo entierro y la incomodidad de los cilicios debajo de las apretadas ropas. No regresó a su casa, sino hasta las 11 de la noche, lo que nos hace pensar como en el siglo XVIII había poca comprensión de la limitación de actividades para los niños. Entonces se descubrieron las heridas de los alfileres y los pellizcos, y la curaron con aguardiente provocándole una buena dosis de dolor. Pasó el resto de la noche con calentura. ${ }^{36}$

No sabemos si María Ignacia siguió estas prácticas disciplinarias durante su vida conventual. Sus cartas al padre Valls, escritas ya desde un lecho de enferma cerca del final de su vida, se concentraron en su mundo visionario, hecho razonable ya que la penitencia corporal no le hubiera sido posible entonces. Pero la adopción de esas prácticas en sus primeros ańos sugieren que sería muy posible se siguieran dentro del convento. ${ }^{37}$ En Nueva Espańa, los testimonios de la madre María Magdalena Lorravaquio, por ejemplo, indican que comenzó un programa de disciplinas corporales en su casa para reafirmar su vocación religiosa. Mariana de Jesús Nazareno vistió el hábito carmelita a la edad de cuatro años con la aprobación de sus devotos padres, mientras otras, aunque excepcionalmente, lograron ser admitidas en un convento desde edad muy temprana con miras a una profesión al llegar a la edad requerida. ${ }^{38}$ Las disci-

${ }^{36}$ Cuaderno 3, fol. 10-10v. Nótese el uso de medicina casera. El "moro" puede haber sido un afromexicano.

${ }^{37}$ Otras religiosas novohispanas y españolas fueron muy adeptas a las disciplinas corporales, que llegaron a ser un elemento de rigor en la escritura testimonial conventual.

${ }^{38}$ Véase Asunción Lavrin, Brides of Christ. Conventual Life in Colonial Mexico (Stanford: Stanford University Press, 2008, 28-29); Kathleen Myers, A Wild Country, 24-25, también describe las prácticas ascéticas de María de San José. 
plinas corporales fueron práctica común en algunos conventos observantes, y algunas monjas que veían en los mismos una forma de imitación de Jesucristo. ${ }^{39}$

\section{VISIONES Y ÉXTASIS. LA VIDA ESPIRITUAL}

Las cartas de María Ignacia al padre Valls nos revelan que ya como monja estaba acostumbrada a tener visiones diarias y que en las mismas tenía relaciones de intimidad espiritual con Jesucristo, Dios, la virgen María, san José, y numerosos santos. Dada la intensidad de sus experiencias visionarias como religiosa no es de extrańar que su raíz se encontrara en su nińez. Otras religiosas novohispanas y españolas tuvieron muchas dudas de sí mismas y sus vivencias devocionales y se entregaban a episodios de escrupulosidad, autoacusaciones y angustias extenuantes. No así María Ignacia quien, si bien, expresó desasosiegos de cuando en cuando, tuvo una confianza implícita en su capacidad de acceso a seres divinos y la autorización que recibía de ellos. Teniendo en cuenta que estos recuerdos de su infancia fueron escritos en los últimos meses de su contacto con el padre Valls, no es de extrañar que su mundo visionario como adulta se filtrara en los capítulos de su infancia que logró escribir. Sería de otro modo muy difícil aceptar que una criatura de menos de seis años lograra comprender la naturaleza de la Trinidad, como nos afirma, o tener arrobos místicos y conversaciones con Cristo, o tener visiones descritas perfectamente después de más de un cuarto de si-

${ }^{39}$ A modo de ejemplo, véase Miguel Batista de Lanuza, Vida de la bendita madre Isabel de Santo Domingo, compañera de santa Teresa de Jesús (Madrid: Imprenta el Reino, 1638). El biógrafo cuenta que "siendo Priora de Pastrana, usó de este ejercicio: que a imitación de Christo mandaba que la atasen a un poste y la azotasen las religiosas hasta que la dejaban bańada (toda) cubierta de su sangre [...] Supo Santa Teresa este modo de penitencia que causaba horror a las hermanas y "mandó que no lo usase"', p. 355. En Nueva España los cronistas de la orden del Carmelo, por ejemplo, elogian los actos de disciplina corporal como medio indispensable para alcanzar una alta espiritualidad. Véase Fr. Agustín de la Madre de Dios, Tesoro escondido en el Santo Carmelo mexicano... (México: Probursa y Universidad, 1984). Los diarios de la franciscana sor María de Jesús Felipa también detallan sus continuas disciplinas. María de Jesús Felipa, "Diarios", AHPFM, Fondo Provincia, manuscritos, caja 5, núms. 9, 10 y 11 y caja 6, núms. 12 y 13, 14 y 15 . 
glo. Entramos en terreno resbaladizo, pero uno muy frecuentado por las religiosas virreinales. ${ }^{40}$

Los reclamos visionarios de María Ignacia comenzaron durante su primera comunión, durante la cual vio a Cristo sacando un relicario de su pecho donde se alojaban las tres personas. Después de sus oraciones ella recibió tres azucenas de las tres personas. En sus hojas tenían un letrero que leía: "ofréceme en agradecimiento tu virginidad". ${ }^{41}$ A esta visión siguieron otras en las cuales estaban las de "la creación del mundo como lo dice el Génesis", la desobediencia de Adán y las calidades y poderes de las tres personas sagradas de la Trinidad.

En su narración María Ignacia se dirige directamente al padre Valls en las exclamaciones y comentarios que intercala en esas memorias:

Ay, padrecito, que confusión y vergüenza me causa ver lo mal que he correspondido y correspondo tantos beneficios y tanto amor y tantos amores que ese Dios Nuestro Señor amantísimo me ha hecho y me hace. Se deshace mi corazón para dar gracias al Señor; se enardece y en muchas ocasiones no puedo escribir porque se lleva mi corazón por mucho rato. ${ }^{42}$

Aquí es donde se encuentra el salto entre la experiencia de una monja profesa y la memoria de una nińez en la cual comenzaba a apuntarse la inclinación a la vida religiosa. No hay que dudar de la sinceridad de la emoción religiosa en la nińa para admitir que, como recuerdo, era muy difícil separar su identidad ya madura de lo que pretendía ser una experiencia infantil. En varias ocasiones se mueve del recuerdo de la niñez a la alocución al confesor que se suponía estaría leyendo el texto. La inclusión del lector en el discurso de la

40 "En esto encendió mi Corazón el divino espíritu, no lo sé decir, y casi fuera de mí, me tuvo el Señor toda la semana de Pascua del divino espíritu, y el día de la Santísima Trinidad me hizo el Señor Dios Nuestro mayores beneficios que hasta entonces había hecho conmigo y con mayor claridad me manifestó el amabilísimo misterio de su admirable trinidad. Todo es inexplicable". Cuaderno 3, fol. 11.

${ }^{41}$ Cuaderno 2, fol. 3-3v.

${ }^{42}$ Cuaderno 2, fol. 5 . 
memoria revela la consciencia de la escribiente y trasciende el recuerdo transportándose a su realidad frente a Valls. El recuerdo tiene la intención de renovar -ya como monja-su gratitud a Dios y explicar cómo una fe que echó sus raíces tan tempranamente, renueva y promueve estados de inefable espiritualidad como profesa.

Volviendo a su niñez, narra como a esa tempranísima edad experimentó arrobos que le quitaban el sentido por varias horas. Esas experiencias tomaron lugar tanto en la iglesia como en el pesebrecorral de su casa donde hacia sus disciplinas. Durante esas visiones el Señor la llama "esposa" como si ya fuera una monja profesa. El abrazo del Señor "quemaba vivo" su corazón. En uno de esos arrobos durante semana santa vio a la Sagrada Familia, y a san Pedro y san Francisco, quienes rogaron al Señor por ella y por el niño que la había ayudado a tirar las muñecas en un pozo. Más a propósito de la experiencia de una niña, sin embargo, es que vio a san Francisco y san Pedro de Alcántara en forma de frailecitos de su tamańo, y que la virgen María le había explicado que era una prueba del amor de Dios que los viera como niños de su estatura. ${ }^{43}$ De hecho se le explica que sus revelaciones a tan temprana edad son el intento de Dios para que a través de su vida comprendiera su pasión y se dispusiera a sufrir por Él. ${ }^{44}$ La técnica de la explicación del significado de sus visiones es la que sigue no sólo María Ignacia sino, por ejemplo, María de Jesús Felipa, en sus escritos. En el caso de María Ignacia no cabe duda que su intención -consciente o no-era la de conferir a su niñez un destino de elección que explicara su decisión de tomar el velo y, de hecho, su vida como religiosa. Otro pasaje de interés en ese deseo de reconfiguración es uno en el que narra cómo después de haber experimentado una visión antes de tomar la primera comunión quedó inmovilizada y no pudo responder a la llamada de su casa. Cuando la hallaron en el pesebre todo cubierto de basura y tierra, la castigaron. Lo que recuerda haberle importado no fue el

${ }^{43}$ Cuaderno 3, fol. 3.

${ }^{44}$ Cuaderno 3, fol. 4. "Anímate tú, y pues desde tan pequeña edad te hemos beneficiado y traído a nuestro conocimiento y amor y razón que vayas ahora al monte de la mirra y seas en algún modo compańera y partícipe de las penas de tu amado Redentor”. 
castigo, sino el hecho de que el Señor se quedó de nuevo "escondido" para ella tras habérsele revelado en esa significativa experiencia. Así, siguió dándose sus penitencias y preparándose para la comunión. Estos estados de arrobo se repiten, especialmente, después de haberse confesado y comulgado, momentos en los cuales el Señor entra en su pecho y ella le da mil afectos amorosos, experiencias que mimetizan las que describía a su confesor Valls en su epistolario de adulta, y que abundan en la escritura de otras religiosas espirituales. En estas visiones que dice haber tenido de niña, el Señor le habla directamente usando la táctica del diálogo que fue el estilo utilizado en sus cartas al confesor. Durante esas conversaciones se le aclaraban el significado de las apariciones; era alentada para seguir el ejemplo de la pasión de Cristo; recibía elogíos como a una escogida; y recibía ánimo para seguir su elección espiritual. Aquí las conversaciones las pone en boca de una niña de menos de siete años. Se pierden los linderos que deben existir entre la comprensión de un estado de espiritualidad en una mente adulta y el esfuerzo que esa misma mente hace para expresar sentimientos que aparecieron en una edad muy temprana para poder ser expresadas cabalmente. No dudo de su devoción como niña, sino de las visiones y su forma de enunciación como realidades difíciles de ser creíbles como experiencias infantiles.

Es de particular interés como María Ignacia manipula la imaginación de esas visiones, con las herramientas intelectuales que ha adquirido a través de su vida en el convento y del conocimiento que llegó a adquirir a través de su preparación como religiosa y lectora de obras devocionales. Por ejemplo, en una de esas visiones, el Señor abre una cortina (frase de sor Ignacia que traiciona la pretendida inocencia de su experiencia) para revelarle primero su amor, y llegado el momento, el de su Pasión, que a pesar de su corta edad se le da a conocer para que aprecie la munificencia del regalo que recibe. Escribe haber recibido la comprensión de la Pasión no por partes, sino "de montón" o todo junto, como el resumen de todo lo que había experimentado en "los 4 años anteriores". Esa iluminación es como en los "rompimientos" pictóricos barrocos, y es el tipo de comprensión instantánea y completa que caracteriza la revelación divina. Esa revelación fue durante Semana Santa, pero se repite el 
día de Corpus, después de comulgar cuando estuvo en la iglesia con su nana todo el día excepto un breve rato cuando fueron a desayunar a mediodía en casa de su padrino. De nuevo reaparece su retrovisión en el uso de complejos cuadros o escenas creadas intencionalmente para subrayar la pretendida experiencia. Así, se vio como una niña en mantillas que fue llevada a los brazos del "padre eterno y el espíritu santo" para una nueva consagración en la cual se le quitaron las mantillas, se la vistió con una túnica de nácar que significaba su paso a la madurez espiritual con su ofrecimiento de perseverar en una vida dedicada a padecer para servir a Dios. En una ceremonia transformativa, la nińa engalanada se convierte en una hermosa criatura que es alabada por el Señor. ${ }^{45}$ Estas experiencias reales o no- le fueron de gran valor ya que en sus propias palabras y dirigiéndose a su padre espiritual y lector, el padre Valls, "hasta ahora me dura, creciendo siempre más, conforme el señor me favorece". ${ }^{46}$ De aquí se desprende el significado de la memoria autobiográfica. Durante la escritura de su biografía la experiencia devocional se fue desarrollando con la ayuda del confesor, pero la escritora sugiere con su montaje en escena, que estaba ya preinscrita en ella por la voluntad de Dios. Las revelaciones fueron la prueba de su escogimiento y de su destino. Su niñez sería simplemente un preámbulo para una vida que, a través de su planeada autobiografía, hubiera ratificado sus experiencias infantiles. El rescate de ese periodo de su vida se lo debía a su confesor, a quien van destinados sus comentarios, y a la influencia que el mismo había sabido ejercer sobre ella para desatar su lengua. Así escribe, "sólo la obediencia puede darme palabra para decir un poco de algo y hacer que deponga mi natural cortedad". ${ }^{47} \mathrm{El}$ pormenorizar sus recuerdos puede producirle ansias, no cabe duda, pero según escribe lo que parece preocuparla no es el contenido de sus arrobos ni el hecho mismo de haberlos experimentado, sino su cortedad para explicar lo que pretende fue una verdadera experiencia. "Padrecito, apenas puedo decir un algo

${ }^{45}$ Cuaderno 3, fol. 4-4v, 5, 5v. Deduzco que podía tener unos 6 o 7 años cuando recibió esa visión.

${ }^{46}$ Cuaderno 3, 5v.

${ }^{47}$ Cuaderno $5 \mathrm{v}$. 
de lo que en el día de la Santísima Trinidad y en este día de Corpus me manifestó y favoreció el Señor y me contento con sólo decir lo que puedo y entendí en aquel tiempo". La escritura se convierte en vehículo y testimonio de la voluntad de Dios y cuando María Ignacia toma la pluma, se autorrepresenta como un mero recipiente agradecido. Así se demuestra su fe inquebrantable dentro de la cual cabían esas experiencias extraordinarias de comunicación con lo divino.

\section{Conclusiones}

En un artículo publicado en 1987, y que aún tiene una valiosa vigencia, Isabelle Poutrin estudió la autorrepresentación de numerosas monjas españolas durante su niñez. Poutrin contó con un buen número de ejemplos, situación que no tenemos para la Nueva España. ${ }^{48}$ Es preciso recordar sus conclusiones al respecto. Poutrin destaca el proceso de aprendizaje de un sistema de representaciones religiosas que envuelven a las nińas durante sus primeros años y a través de las cuales aprenden los modelos de prácticas ascéticas y de santidad. No cabe duda que María Ignacia tuvo ejemplos de prácticas piadosas en su comunidad y en su propia casa. A pesar de sus rebeldías infantiles y de múltiples castigos probablemente nacidos por la disrupción de regularidades cotidianas del hogar, que era cuna de prácticas religiosas y permitió la influencia temprana de un párroco que la acogió, fomentó la creencia de que podría llegar a tener una vida dedicada a Dios, y la inició en el camino de la observancia católica. En ese hogar también se permitía la práctica de comulgar frecuentemente y de oraciones pidiendo intercesión caritativa de figuras icónicas de la devoción mariana. María Ignacia tenía un altar en su propio cuarto y la privacidad del mismo para disponerse a la comunión y practicar disciplinas a solas. Por otra parte, lo que María Ignacia ve como una serie de sufrimientos y castigos, pueden haber sido expresiones de atención familiar a la niña, como la insistencia de la familia en vestirla bien para que pare-

${ }^{48}$ Isabelle Poutrin, "Souvenirs d'enfance", passim. 
ciese una muñeca. ${ }^{49}$ Era importante, sin embargo, que en la construcción de su niñez existiera un contrapuntó de adversidad para probar la calidad de su resistencia y el empuje irresistible de la voluntad divina. Los castigos y las "privaciones" de que cree haber sido objeto eran necesarios en la narrativa de la mujer adulta y monja devota.

La falta de la memoria de su vida entre sus siete y quince ańos cuando ya seguramente había decidido tomar el velo, deja un gran vacío en nuestra búsqueda del significado de este atentado autobiográfico. Poutrin menciona los ejemplos piadosos de otros familiares y las lecturas de libros de inspiración religiosa, elementos que no aparecen en la narración de María Ignacia, dada su ubicación geográfica en un pequeño pueblo de provincia y en una familia donde la lectura no parece haber sido un factor cultural. Aun careciendo de esos elementos, encontramos que el "mimetismo de la santidad", que menciona Poutrin, florece en las actividades que nos cuenta María Ignacia. Es obvio que sus prácticas de penitencia corporal se encuentran en fuentes no mencionadas pero conocidas por ser frecuentes en la cultura religiosa novohispana. Por ejemplo, la identificación de la nińa con la imitación de la pasión de Cristo es un tema predominante en la espiritualidad espańola desde finales del siglo Xvi. Como apuntan Poutrin y Maureen Flynn, el deseo de padecer, no era extraño en la niñez devota de la península. ${ }^{50}$ Tampoco lo fue en los virreinatos de ultramar y en el pequeño pueblo de Irapuato, Nueva España. También se identifica como rasgo cultural la devoción a la virgen María en su acepción inmaculada, tan favorecida por los franciscanos visitantes en su hogar y su escogimiento de un convento franciscano para su profesión. ${ }^{51}$

La voluntad de reescribir su vida como la de una nińa predestinada se conjuga con el deseo histórico de recordar su experiencia como miembro de su familia. Aquí tenemos el inicio de un camino, la intuición de un destino, la voluntad de reafirmar como esos inicios

${ }^{49}$ Cuaderno 3, fol. 7v.

${ }^{50}$ Maureen Flynn, “The Spiritual Uses of Pain in Spanish Mysticism”, Journal of the American Academy of Religion 64(2) (verano 1996): 257-78.

${ }^{51}$ Cuaderno 3, fol. 7. 
fueron ya un augurio de quien llegaría a ser. La fórmula usada fue la mezcla de información factual sobre su niñez con descripciones de su mundo visionario y expresiones de su fe. Los linderos entre estas tres orientaciones no están bien demarcados a pesar de que la elección de cada uno de los recuerdos tuvo un significado especial para la monja. El filtro de su memoria escogería aquellos que pensaba dieron significado a su vida hasta el momento de su escritura y no es sorprendente que los mismos tienen muchos rasgos comunes con lo que expresaba en su epistolario, donde explaya su repertorio de experiencias visionarias que podía utilizar en su autobiografía. La similaridad sólo reafirma la identidad que logró construir a través de muchos años de vida religiosa. ${ }^{52}$

En cuanto al valor de las descripciones de sus arrobos y su interpretación, creo que es muy posible que la nińa no se sintiera rodeada de afectividad y que sus arrobos, si los tuvo, fueran un medio de encontrar otra fuente de afecto: el de Dios y toda la corte celestial. Los estados de escape espiritual durante los cuales se esfuma la realidad que rodea al individuo y se recrea otro mando lleno de actividad $\mathrm{y}$ afectividad que proveen a quienes experimentan esas situaciones una fuente constante de amor y una revaloración de su persona como acreedora de atención y capaz de ejercitar un rol protagónico en una agenda de origen divino. Si bien, la persona expresa su "bajeza”, su pequeñez e incapacidad, las acciones de los seres divinos niegan constantemente esa autopercepción y la elevan por encima de sus aprensiones, dándole momentos de plena confianza en sí misma. Esta capacidad de dotar al individuo con una capacidad receptiva para ver, sentir y comprender, y una capacidad creativa para escribir sobre su experiencia es lo que caracteriza a los estados de arrobo.

Este intento de biografía es un ejemplo de cómo una religiosa trató de comprender el escogimiento de Dios en su persona, y como esa elección se le hizo manifiesta a pesar de que aún no tenía capacidad para expresarlas sino a través de actividades que se le habían

52 Asunción Lavrin, "Visiones y devociones”, 10. Pozuelo Yvancos comenta como la autobiografía tiene cierta proximidad a la epístola. Véase De la autobiografia, p. 22. También se puede comparar a una confesión en el caso de una religiosa. 
enseñado a ver como expresiones de su creencia en los fundamentos de su religión. De ahí esas actividades de autodisciplina, largas horas de oración, y participación en los rituales festivos y rituales como la comunión. Pero no podemos olvidar que la voz que se escucha en esta miniautobiografía es la de una mujer madura que se autoanaliza a través de su memoria. Los incidentes de su vida infantil se ponen al servicio de dos causas: la de explicarse a sí misma frente a su confesor y la de revalidar sus experiencias visionarias como religiosa profesa al retrotraerlas a la niñez, periodo que se asume inocente, abierto y carente de dobleces. Por lo tanto, la fe que expresa en esa tierna edad se ve como una experiencia pura que sellará el resto de su vida y explicará su destino dentro del claustro. Es posible que el padre Valls comprendiera el valor del relato de la infancia como herramienta docente, no sólo para la religiosa, sino para los lectores, a quienes está explícitamente dedicada en la portada.

De acuerdo con Voaden y Volf, las visiones infantiles en las mujeres reflejan una diferencia entre hombres y mujeres que seguían los dictados de la percepción de la niñez en el periodo medieval. Al considerarse a las mujeres como vasos débiles de la fe, agobiadas por el peso de su propia materialidad corpórea que restringía su capacidad intelectual y las hacía más afectas a las tentaciones y a las fuerzas diabólicas, las mujeres debían defender su estatus visionario como propio y confiable. Usando la experiencia de la niñez como un periodo formativo de su espiritualidad y recordando experiencias de contactos con el mundo celestial, las visionarias enraizaban su papel como mensajeras de revelaciones y enseñanzas que provenían de las fuentes más altas del mundo espiritual. ${ }^{53}$ María Ignacia dice haber tenido no sólo visiones sensoriales, sino la percepción de verdades teológicas aprehensibles por el intelecto como la esencia de la Trinidad, a lo que agrega estados de arrobamientos. Pero no sólo la tradición medieval abrió el mundo visionario a niñas de poca edad. En la abundante cosecha de vidas que tenemos para la Espańa contrarre-

${ }^{53}$ Voaden y Volf, "Visions of my Youth". Las autoras revisaron las Vitae de 27 santas y visionarias laicas y 13 santos y maestros de la fe cristiana entre los siglos XI y XV en Inglaterra y Europa. 
formista y en algunas biografías novohispanas, la nińez femenina se presenta como un estado de inicio de espiritualidad y prácticas penitenciales. Así que en este aspecto, María Ignacia del Nino Jesús, educada espiritualmente en el último cuarto del siglo XviII, continuaba una tradición de escritura femenina que la hermanaba con todas sus predecesoras religiosas. ${ }^{54}$

Las prácticas infantiles de María Ignacia presagian sus prácticas adultas y son bastante similares a las de muchas monjas cuyos escritos se han podido rescatar o de quien sus biógrafos han dejado testimonios fidedignos. Su vida se mueve entre dos polos desde la nińez: las prácticas de ascetismo penitencial y las experiencias visionarias. La formación de muchas monjas culminó en su vida espiritual una vez que profesaron. La dirección espiritual de los siglos XVII y XVIII no tuvo duda alguna sobre el valor de la penitencia para domar el cuerpo y acomodar el espíritu a lo que se veía como el modelo más sublime de la vida religiosa: el de la imitación de la pasión de Cristo. Por otra parte, el escape de la vida ascética se realiza a través de las visiones que son usualmente muy confortantes. O sea que las visiones otorgan a quienes las experimentaban el calor afectivo que permitía sobrellevar las prácticas penitenciales y la vida claustral. ${ }^{55}$ Lo que podemos apreciar de esos cortos recuentos infantiles es precisamente la formulación de un preámbulo a la vida claustral en la cual

\footnotetext{
${ }^{54}$ A modo de ejemplo, véanse, Ldo. Pedro Alamin, Sumario de la vida de la venerable madre sor Juana de Jesús María, monja del convento de S. Clara de Burgos (Zaragoza: herederos de Diego Dormer, 1676). A los 4 ańos ya recibía visitas de los santos y en una aparición Jesús, niño, la declara su esposa. Véanse páginas de 3 a 9; María Josefa Lina de la Canal, se confesaba a los seis años, se penitenciaba y vivía a modo de reclusa en su casa. Véase Juan Benito Díaz de Gamarra, Ejemplar de religiosas. Vida de la muy reverenda madre sor María Josefa Lina de la Canal (México: Alejandro Valdés, 1831). Sor María Josefa vivió en el siglo XviII.

${ }^{55}$ Ejemplo de María de Jesús Felipa, cuya madre espiritual la somete a prácticas penitenciales que imponen la sumisión del cuerpo y de la voluntad y que sólo de vez en cuando le regala alguna expresión de afecto a la discípula. El confesor de María Felipa no era muy efectivo en su dirección afectiva-espiritual y así fueron muchos otros confesores según nos cuentan algunas religiosas que se empeñaron en la búsqueda de un confesor compasivo y atento. El confesor de María Felipa sabía de las prácticas penitenciales que le imponía su madre claustral y al parecer las aprobaba con su conducta de no intervención. Véase fuente en la nota 39.
} 
visión y penitencia se conjugaban para regir su imaginario espiritual. ${ }^{56} \mathrm{~A}$ pesar de la cortedad de este texto, el mismo nos permite ver como se inició el camino de una vida religiosa, de la cual sólo nos quedan su inicio y su despedida. En esos inicios ya se presagia la despedida y ahí radica su valor para las lectoras de hoy.

\section{Archivos}

Archivo Histórico de la Provincia Franciscana de Michoacán, Celaya, México (AHPFM).

Biblioteca Nacional, México.

\section{BIBLIOGRAFÍA}

Alamin, Pedro. Sumario de la vida de la venerable madre sor Juana de Jesús María, monja del convento de S. Clara de Burgos. Zaragoza: herederos de Diego Dormer, 1676.

Aren Janeiro, Isidoro. "Libro de la Vida de Teresa de Jesús: Teresa de Cepeda y Ahumada reconstruida por Teresa de Jesús". En Mujeres, espacio y poder, ed. Mercedes Arriaga Florez et al., 1726. Sevilla: Arcibel Editores, 2006.

BÁEz RIVERA, Emilio Ricardo. Visiones y experiencias extraordinarias de la primera mistica novohispana. Autobiografía de una pasionaria de amor de Cristo. México: Derechos reservados, 2013.

- "Symbolica mystica: la venerable María Magdalena de Lorravaquio Muńoz y sus tangencias con lo sagrado prehispánico”. En Vida conventual Femenina. Siglos XVI-XIX, comp. Manuel Ramos Medina. México: Centro de Estudios de Historia de México-Carso, 2013.

Batista de Lanuza, Miguel. Vida de la bendita madre Isabel de Santo Domingo, compañera de Santa Teresa de Jesús. Madrid: Imprenta el Reino, 1638.

${ }^{56}$ Durante el último tramo de su vida cuando María Ignacia tenía al padre Valls como director espiritual, las penitencias ya no eran posibles debido a su enfermedad. El padre Valls fue, al parecer, un director afectuoso y comprensivo que permitió a María Ignacia dedicarse a cultivar el aspecto visionario de su espiritualidad. 
Bellido, Joseph. Vida de la venerable madre sor Mariana Ana Águeda de San Ignacio, primera priora del religiosísimo convento de dominicas recolectas de Santa Rosa de la Puebla de los Ángeles. México: Imprenta de la Biblioteca Mexicana, 1758.

BieŃKo, Doris. "Los territorios del yo. La autobiografía espiritual en la época virreinal". En De sendas, brechas y atajos. Contexto y crítica de las fuentes eclesiásticas, siglos XVI-XVIII, coord. Doris Bieñko de Peralta y Berenise Bravo Rubio, 36-60. México: ENAH, INAH, Conaculta, Promep, 2008.

. "Voces del claustro. Dos autobiografías de monjas novohispanas del siglo XvII". Relaciones. Estudios de Historia y Sociedad xxxv (139) (verano 2014): 157-194.

Cruz, Sor Juana Inés de la. "Respuesta de la poetisa a la muy ilustre sor Filotea de la Cruz". En Obras completas. México: Editorial Porrúa, 1969.

Díaz de Gamarra, Juan Benito. Ejemplar de religiosas. Vida de la muy reverenda madre sor María Josefa Lina de la Canal. México: Alejandro Valdés, 1831.

Durán López, Fernando. Un cielo abreviado. Introducción crítica a una historia de la autobiografia religiosa en España. Madrid: Fundación Universitaria Española y Universidad Pontificia de Salamanca, 2007.

Flynn, Maureen. "The Spiritual Uses of Pain in Spanish Mysticism". Journal of the American Academy of Religion 64(2) (verano 1996): 257-278.

Glantz, Margo. Sor Juana Inés de la Cruz: ¿Hagiografía o autobiografia? México: Grijalbo, unam, 1995.

GómEz, Fr Joseph. Vida de la venerable madre Antonia de san Jacinto... hija el real ... convento de santa Clara de Jesús... de Querétaro. México: Imprenta de Antuerpia, 1689.

Herpoel, Sonja. "Un mar de misterios": la religiosa española ante la escritura". En Breve historia feminista de la literatura española (en lengua castellana). Iv. La literatura escrita por mujer. Desde la Edad Media hasta el siglo XVIII, coord. Iris Zavala, 205-223. Puerto Rico y Barcelona: Anthropos, Editorial de la Universidad de Puerto Rico, 1997. 
Herpoel, Sonja. A la zaga de Santa Teresa: Autobiografia por mandato. Amsterdam: Rudopi, 1999.

LaVRIN, Asunción. "La vida femenina como experiencia religiosa: biografiar y hagiografía en Hispanoamérica colonial. Colonial Latin American Review 2(1-2) (1993): 27-51.

. "La madre María Magdalena Lorravaquio y su mundo visionario". Signos Históricos (13) (enero-junio 2005): 22-41.

. "María Marcela Soria: Una Capuchina queretana". En Diálogos espirituales. Manuscritos femeninos hispanoamericanos. Siglos XVI-XIX. Asunción Lavrin y Rosalva Loreto, 74-116. Puebla: BUAP, UDLA, 2006.

. "La construcción de la niñez en la vida religiosa. El caso novohispano". En Historia de la infancia en América Latina, coord. Pablo Rodríguez y María Emma Manarelli, 121-144. Bogotá: Universidad Externado de Colombia, 2007.

. Brides of Christ. Conventual Life in Colonial Mexico. Stanford: Stanford University Press, 2008.

. "La religiosa y su confesor: Epistolario de una clarisa mexicana, 1801-02", Archivum Franciscanum Historicum (105) (enero-diciembre 2012): 455-478.

. "Visiones y devociones. Maria Ignacia del Niño Jesús a través de su epistolario". En Vida conventual Femenina. Siglos XVIXIX, comp. Manuel Ramos Medina, 345-375. México: Centro de Estudios de Historia de México-Carso, 2013.

. Las esposas de Cristo. La vida conventual en la Nueva España. México: Fondo de Cultura Económica, 2016.

LORETo López, Rosalva. "Escrito por ella misma. Vida de la Madre Francisca de la Natividad". En Monjas y beatas. La escritura femenina en la espiritualidad barroca novohispana. Siglos XVII y XVIII, ed. Asunción Lavrin y Rosalva Loreto López, 24-66. Puebla: Universidad de las Américas, Archivo General de la Nación, 2002.

. "Las formas de escritura femenina, un aporte a la espiritualidad barroca novohispana. Siglos XvII y XvIII". En Camino a la santidad, siglos XVI-XX, coord. Manuel Ramos Medina, 69-82. México: Condumex, 2003. 
Madre de Dios, Fr. Agustín de la. Tesoro escondido en el Santo Carmelo mexicano... México: Probursa y Universidad Iberoamericana, 1984.

Myers, Kathleen. Word from New Spain. The Spiritual Autobiography of Madre Maria de San Jose (1656-1719). Liverpool: Liverpool University Press, 1993.

"Fundadora, cronista y mística, Juana Palacios Berruecos/ Madre María de San José (1656-1719)". En Monjas y beatas. La escritura femenina en la espiritualidad barroca novohispana. Siglos XVII y XVIII, ed. Asunción Lavrin y Rosalva Loreto López, 67-110. Puebla: Universidad de las Américas, Archivo General de la Nación, 2002.

Myers, Kathleen y Amanda Powell. A Wild Country Out There in the Garden. The Spiritual Journals of a Colonial Mexican Nun. Bloomington: Indiana University Press, 1999.

Navallo, Tatiana. "La autobiografía conventual colonial", Andes (14) (2003): 1-30, también en http://www.redalyc.org/ pdf/127/12701402.pdf

Ortiz, Mario A., ed. La autobiografía espiritual de la Madre María de San José (1656-1719). Newark: Juan de la Cuesta, 2011.

Petite, Anselmo. Conducta de las almas en el camino de la salvación. Suplemento a la Conducta de Confesores. Madrid: Imprenta de Son Josef Urrutia, 1792.

Poutrin, Isabelle. "Souvenirs d'enfance: L'apprentissage de la sainteté dans l'Espagne moderne". Mélanges de la Casa de Velázquez (23) (1987): 331-354.

. Le voile et la plume. Autobiographie et sainteté feminine dans l'Espagne Moderne. Madrid: Casa de Velázquez, 1995.

Pozuelo Yvancos, José María. De la autobiografia. Teoría y estilos. Barcelona: Crítica, 2006.

Prado Biezma, Javier del, Juan Bravo Castillo y María Dolores PicAzo. Autobiografia y modernidad literaria. Cuenca: Universidad de Castilla-La Mancha, 1994.

Ramírez Montes, Mina. Niñas, doncellas, vírgenes eternas. El convento de Santa Clara de Querétaro. México: unam, 2005.

Rubial, Antonio. "Imprenta, criollismo y santidad. Los tratados 
hagiográficos sobre venerables, siervos de Dios y beatos novohispanos". REDIAL, Revista Europea de Información y Documentación sobre América Latina 8(9) (2001): 43-52, 117-131.

Rubial Antonio y Doris Bieñko de Peralta. "La más amada de Cristo. Iconografía y culto de santa Gertrudis la Magna en Nueva Espańa”. Anales del Instituto de Investigaciones Estéticas (83) (2003): 1-53.

Ruiz Martínez, Cristina. "La moderación como prototipo de santidad: una imagen de la niñez". En De la santidad a la perversion o de por qué no se cumplía la ley de Dios en la sociedad novohispana. Mexico: Editorial Grijalbo, 1986, 49-66.

Salmerón, Pedro. Vida de la venerable madre sor Isabel de la Encarnación, carmelita descalza natural de la ciudad de los Ángeles. México: Francisco Rodríguez Lupercio, 1675.

Teresa de Jesús, Santa. Libro de la vida. Prólogo de Joseph Pérez, ed. Ma. de los Hitos Hurtado. Madrid: Algaba Ediciones, 2007. VOADERN, Rosalyn y Stephanie Volf. "Visions of my Youth: Representations of Childhood of Medieval Visionaries". Gender and History 12(3) (noviembre 2000): 665-684.

Weber, Alison. "The Three Lives of the Vida: The Use of Convent Autobiography". En Women, Texts and Authority in the Early Modern Spanish World, ed. Mara V. Vicente y Luis R. Corteguera, 107-125. Londres: Ashgate, 2003. 